(c) 2020, The Authors. Published by FASS Inc. and Elsevier Inc. on behalf of the American Dairy Science Association ${ }^{\circledR}$. This is an open access article under the CC BY-NC-ND license (http://creativecommons.org/licenses/by-nc-nd/4.0/).

\title{
Precision feed restriction improves feed and milk efficiencies and reduces methane emissions of less efficient lactating Holstein cows without impairing their performance
}

\author{
A. Fischer, ${ }^{*}$ (1) N. Edouard, (1) and P. Faverdin (i) \\ INRAE, Agrocampus-Ouest, PEGASE, 35590 Saint-Gilles, France
}

\begin{abstract}
A possible driver of feed inefficiency in dairy cows is overconsumption. The objective was therefore to test precision feed restriction as a lever to improve feed efficiency of the least efficient lactating dairy cows. An initial cohort of 68 Holstein lactating cows was monitored from calving to end of ad libitum feeding at 196 $\pm 16 \mathrm{~d}$ in milk, with the last $70 \mathrm{~d}$ being used to estimate feed efficiency. For a given expected dry matter (DM) intake (DMI) during ad libitum feeding, offered DMI during restriction was set to observed DMI of the $10 \%$ most efficient cows during ad libitum feeding for similar performance. Feed restriction lasted during 92 $\mathrm{d}$, with only the last $70 \mathrm{~d}$ being used for data analyses. A single diet was fed during ad libitum and restriction periods, and was based on $64.9 \%$ of corn silage and $35.1 \%$ of concentrates on a DM basis. Individual DMI, body weight, milk production, milk composition, and body condition score were recorded, as well as methane emissions. Feed efficiency was defined as the repeatable part of the random effect of cow on the intercept in a mixed model predicting DMI with net energy in milk, maintenance and body weight gain and loss within parity, feeding level, and time. Milk energy efficiency was estimated in the same way, predicting net energy in milk instead of DMI. The 15 least efficient cows ate $2.6 \mathrm{~kg}$ of DM/d more than the 15 most efficient cows during ad libitum feeding with $2 \mathrm{~g} / \mathrm{kg}$ of DMI lower methane yield, but similar daily methane emissions. Feed restriction decreased DMI by $2.6 \mathrm{~kg}$ of DMI/d for the least efficient cows, which was $1.8 \mathrm{~kg}$ of DMI/d more than the most efficient cows, and decreased daily methane emissions by $49.2 \mathrm{~g} / \mathrm{d}$ for the least efficient cows, which was $22.4 \mathrm{~g} / \mathrm{d}$ more than the most efficient cows. Feed restriction had no significant effect on milk, body weight, or body weight change. Feed restriction
\end{abstract}

Received September 26, 2019

Accepted December 31, 2019.

*Corresponding author: amelie.fischer67@gmail.com reduced the variability of both milk energy and feed efficiencies, as shown by a decrease of their standard deviation from 0.87 to $0.69 \mathrm{~kg}$ of $\mathrm{DM} / \mathrm{d}$ for feed efficiency and from 1.14 to $0.65 \mathrm{UFL} / \mathrm{d}$ for milk energy efficiency. Despite narrow efficiency differences, the most efficient cows during ad libitum feeding remained more efficient during feed restriction $(\mathrm{r}=0.46$ for feed efficiency and 0.49 for milk energy efficiency). The 2 efficiency groups no longer differed in feed efficiency during precision feed restriction. Precision feed restriction seemed to bring the least efficient cows closer to the most efficient cows and to reduce their methane emissions without impairing their performance.

Key words: dairy cow, feeding level, residual feed intake, methane

\section{INTRODUCTION}

A promising way for dairy farmers to be more competitive is to increase the efficiency of resource use while reducing the environmental footprint. Among those resources, feed is the first cost of dairy cow systems, and represents about $46 \%$ of the total costs in the United States (USDA ERS, 2019) and about 50\% in the European Union (European Commission, 2018). Feed efficiency has been improved for decades, indirectly through selection based on higher milk production. While increasing cows' milk production potential, the requirements for maintenance have been increasingly diluted, resulting in more energy being converted into milk, and proportionally less into maintenance (Vandehaar, 1998). To directly improve feed efficiency, several levels can be considered, starting with the farm-herd level down to animal level. For example, increasing calving interval, or increasing longevity of cows, or decreasing age at first calving have been identified as levers improving feed efficiency (Vandehaar, 1998). Expected gains with those levers are significant, and are technically and economically feasible. Improving feed efficiency on an animal level can be developed through selection by including feed efficiency in the selection in- 
dex. Feed efficiency has a small and variable heritability in dairy cows $\left(\mathrm{h}^{2}=0.05-0.23\right.$; Hardie et al., 2017 ; $\mathrm{Li}$ et al., 2017; Hurley et al., 2018). This low heritability requires a large reference population to be monitored to develop a robust index (Gonzalez-Recio et al., 2014). The limited access to individual feed intake records limits the creation of a large reference population. Alternatives to selection have therefore to be considered, such as directly improving feed efficiency of the least efficient cows.

The most efficient cows are consuming less feed than the average of the herd fed the same diet at similar production levels (milk, gestation, body reserves change, maintenance). The question is then to understand why other cows fed the same diet, and performing at similar levels of production, consume more feed than expected. This overconsumption of feed might impair their digestibility because digestibility decreases with increasing DMI (Colucci et al., 1982; Sauvant et al., 2018). Applying a feed restriction to the least efficient cows may then improve their feed efficiency without compromising their production performance. Feed restriction is known to improve efficiency of nutrient use, with usually a significant decrease in milk volume and milk solids production (Ben Meir et al., 2019; Herve et al., 2019; Santana et al., 2019). In these studies, animals were all restricted at the same level. However, given the differences in feed efficiency, animals should not be restricted at the same level: the less efficient an animal is, the more feed restricted it should be. Precision feeding is known for improving feed efficiency of dairy heifers without impairing their performance (Pino et al., 2018). Precision feeding can also be achieved by adjusting individual concentrate intake, available through an automatic concentrates dispenser, to optimize the conversion of expensive feeds in the diet into milk (André et al., 2010).

This research aims at improving feed efficiency of lactating dairy cows through precision feed restriction. If overconsumption is the reason for lower efficiency, and if consequently it decreases digestibility, our hypothesis is that precision feed restriction will improve cows' feed efficiency without impairing their performance and milk energy efficiency. Moreover, it will also increase digestibility and thus methane released per DMI.

\section{MATERIALS AND METHODS}

Experimentation was performed at the INRAAgrocampus-Ouest UMR PEGASE research facility of Mejusseaume (Le Rheu, France). The protocol has been approved by the ethical committee and the French Ministry of Higher Education, Research and Innova- tion (Authorization of the French Ministry of Higher Education, Research and Innovation reference APAFIS 3122-2015112718172611).

\section{Experimental Design}

An initial group of 68 Holstein cows was housed in a freestall barn with free access to water. Calvings were grouped in autumn 2016 over 69 d. These cows were monitored for feed efficiency from calving to the end of June 2017, which matches the end of lactation. All cows were fed the same diet, either ad libitum from calving to March 26, 2017 (196 $\pm 16 \mathrm{~d}$ on average), or restricted between March 26, 2017, and June 25, 2017 (91 d).

The objective was to apply precision feeding to cows less efficient than the $10 \%$ most efficient cows, and see if this precision feeding would improve their feed efficiency. To do so, feed offered during restriction was calculated as the expected feed intake if cows would have been as efficient as the top $10 \%$ most efficient cows $(\mathrm{n}=6$ cows $)$ for similar energy outputs. All cows could not be kept in the study during the feed restriction part for practical reasons. We therefore only kept 30 cows without health issues, including 19 primiparous cows, identified as the 15 cows with the lowest residual feed intake (RFI; the most efficient) and the 15 cows having the highest RFI (the least efficient) during ad libitum feeding (Figure 1A). During ad libitum feeding, the $10 \%$ most efficient cows $(n=6)$ ate on average 1.7 $\mathrm{kg}$ of $\mathrm{DM} / \mathrm{d}$ less than the average DMI of the 68 cows for similar energy outputs (Figure 1B). The 30 cows were therefore fed their expected daily DMI during ad libitum feeding, minus these $1.7 \mathrm{~kg}$ of $\mathrm{DM}$, to be fed at the same level as the most efficient cows (Figure 1C). This feed restriction was defined as precision feed restriction because the level of feed restriction increased with feed inefficiency: the less efficient a cow was during ad libitum feeding, the more feed restricted she was. Only the 6 most efficient cows, used as a reference to estimate expected efficient feed intake, were not submitted to feed restriction.

\section{Phenotypic Measurements}

To make ad libitum and restriction feeding periods comparable, the same period length was chosen for both periods. The feed restriction period lasted $92 \mathrm{~d}$. The first $22 \mathrm{~d}$ of data, associated with the time needed for a cow to adapt to the feed restriction, were discarded. Each period included the last $70 \mathrm{~d}$ of data.

Cows were fed individually with an automatic wagon preparing and distributing each cow's diet individually 


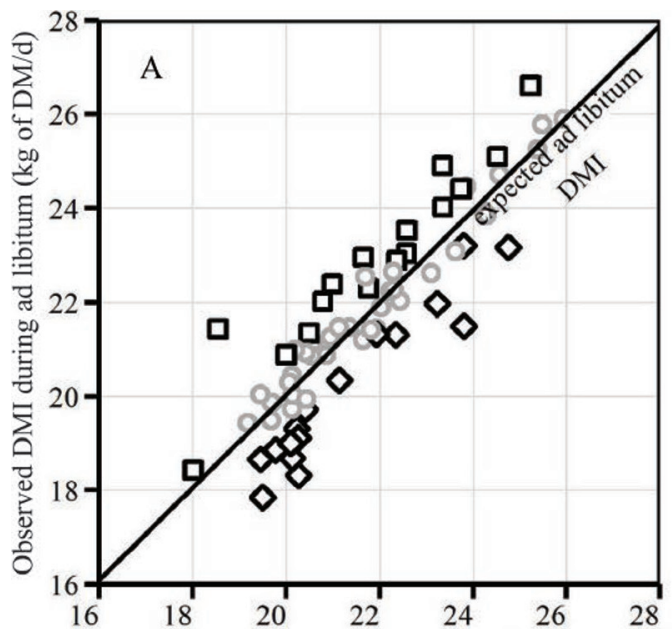

Expected DMI during ad libitum feeding ( $\mathrm{kg}$ of DM/d)

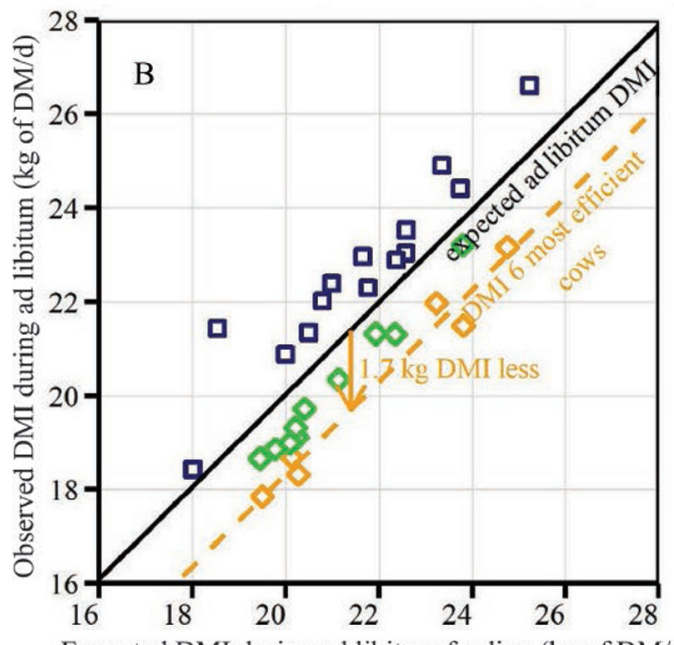

Expected DMI during ad libitum feeding ( $\mathrm{kg}$ of DM/d)

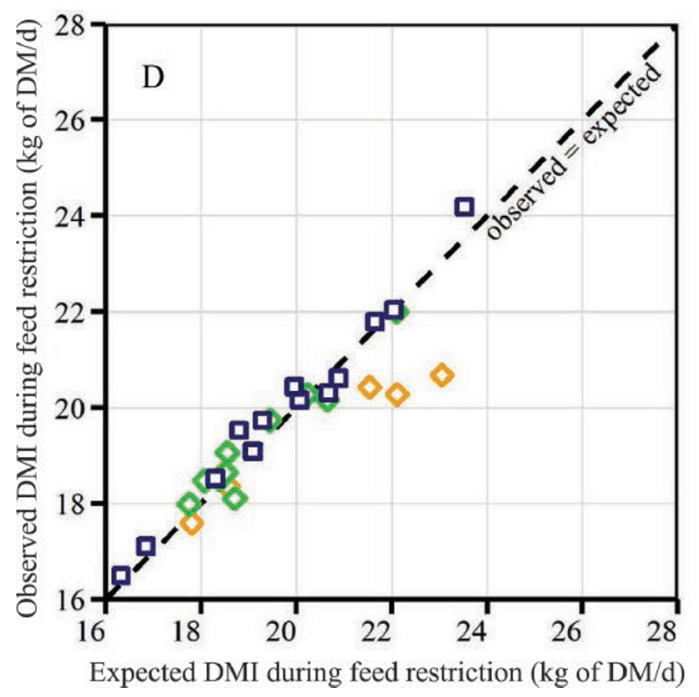

Efficiency group

$\diamond$ most efficient

口 least efficient

- medium efficient

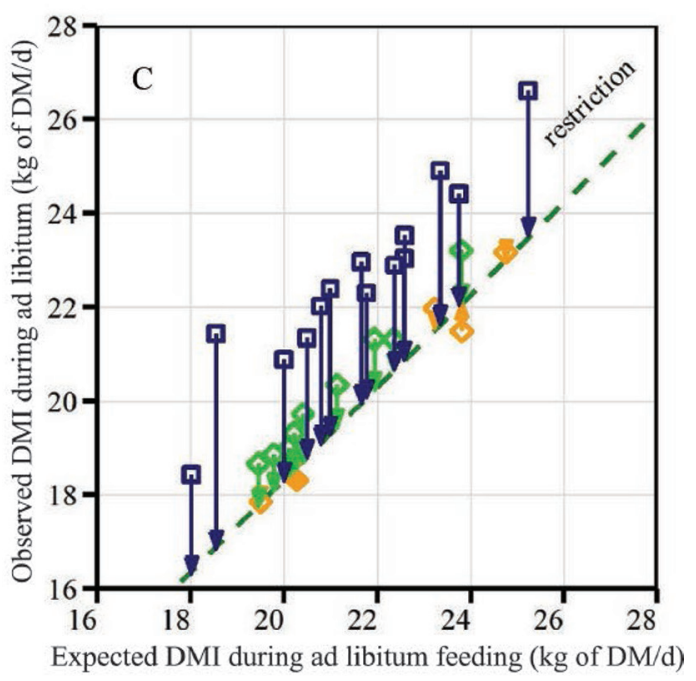
Efficiency group
- most efficient
- 6 most efficient
- least efficient

Figure 1. Methodology for precision feed restriction: (A) identification of the 15 most and 15 least efficient cows out of 68 cows during ad libitum feeding, (B) estimation of the average difference between expected DMI during ad libitum feeding (solid regression line in black) and observed DMI of the 6 most efficient cows (dashed orange line), (C) estimation of feed to offer during the feed restriction period (shown by arrows), and (D) comparison of observed and expected DMI during feed restriction. 
Table 1. Diet composition and analysis during the ad libitum period and feed restriction period

\begin{tabular}{|c|c|c|c|c|}
\hline Item & \multicolumn{2}{|c|}{ Ad libitum } & \multicolumn{2}{|c|}{ Feed restriction } \\
\hline \multicolumn{5}{|l|}{ Feed composition (\% of DM) } \\
\hline Soybean meal & 17.6 & 1.0 & 18.0 & 1.1 \\
\hline Dehydrated alfalfa & 7.8 & 0.7 & 8.3 & 0.8 \\
\hline Energy concentrate + minerals and vitamin complement ${ }^{2}$ & 9.3 & 2.1 & 9.3 & 1.4 \\
\hline $\mathrm{CP}(\mathrm{g} / \mathrm{kg})$ & 148 & 4 & 153 & 5 \\
\hline $\operatorname{ADF}(\mathrm{g} / \mathrm{kg})$ & 201 & 5 & 201 & 3 \\
\hline NDF $(\mathrm{g} / \mathrm{kg})$ & 367 & 5 & 372 & 5 \\
\hline Starch $(g / k g)$ & 193 & 5 & 184 & 3 \\
\hline Net energy for milk (UFL $\left.{ }^{3} / \mathrm{kg}\right)$ & 0.915 & 0.003 & 0.919 & 0.003 \\
\hline MP (g/kg) & 99 & 2 & 100 & 2 \\
\hline
\end{tabular}

${ }^{1} \mathrm{SD}$ were calculated using the day-to-day change in offered diet composition on an individual cow basis.

${ }^{2}$ This concentrate included $17.8 \%$ wheat, $17.8 \%$ corn, $17.8 \%$ sugar beet pulp, $17.8 \%$ barley, $13 \%$ wheat bran, $3 \%$ beet molasses, $0.9 \%$ oil, $0.9 \%$ salt, $11 \%$ minerals and vitamin complement (including $6 \%$ phosphorus, $24 \%$ calcium, $5 \%$ magnesium, and other minerals and vitamins).

${ }^{3} \mathrm{UFL}$ (unité fourragère lait) is the net energy for milk production brought by $1 \mathrm{~kg}$ of reference barley and is equivalent to $7.12 \mathrm{MJ}$ of net energy (INRA, 2010).

twice a day after each milking (0700 and $1600 \mathrm{~h})$. Daily intake was estimated as the difference between daily offered feed and the next morning's refusals. Each cow was fed in her own manger, only accessible by one cow thanks to identification with her neck collar chip. The diet included corn silage, soybean meal, dehydrated alfalfa, and a mix of energy concentrates, minerals, and vitamins (Table 1). Each diet ingredient was sampled once a week for concentrates, and once a day for the forages to estimate individual feed DMI. A bulk sample was taken for each ingredient and silo to analyze diet nutritive value. Diets used for both feeding levels had the same composition and nutritive values with about $0.92 \mathrm{UFL} / \mathrm{kg}$ of $\mathrm{DM}(=6.55 \mathrm{MJ}$ of $\mathrm{NE} / \mathrm{kg}$ of $\mathrm{DM})$ and about $99 \mathrm{~g}$ of MP per $\mathrm{kg}$ of DM (Table 1). One unité fourragère lait (UFL) is the net energy in milk produced by $1 \mathrm{~kg}$ of reference barley and is equivalent to $7.12 \mathrm{MJ}$ of net energy (INRA, 2010).

Milk yield was recorded at each milking with milk meters (DeLaval, Tumba, Sweden). Milk fat and protein concentrations were analyzed by mid-infrared spectrometers (Lillab, Chateaugiron, France) twice a week, from morning and afternoon milk samples pooled relative to the morning and afternoon milk production. Cows were weighed automatically the morning right after the first milking (W-2000, DeLaval) so that the BW was not affected by the weight of milk in the udder. All cows were scored for body condition once a month by 3 trained persons according to the scale developed by Bazin (1984), going from 0 for an emaciated cow to 5 for a fat cow with 0.25 -unit increments.

Part of the energetic concentrates were distributed individually at 2 GreenFeed units (C-Lock Inc., Rapid
City, SD; https://www.c-lockinc.com/shop/automated -emissions-measurement/greenfeed-large-animals/). A GreenFeed unit is designed as an electronic concentrate dispenser to measure methane and carbon dioxide emissions each time a cow visits the feeder. The GreenFeed dispenses small drops of energy concentrate (30 $\mathrm{g} /$ drop) to maintain cow's head in the feeder for a long enough period (around $3 \mathrm{~min}$ ). A maximum of $720 \mathrm{~g}$ of concentrates was offered daily at the GreenFeed. Each GreenFeed unit can record methane emissions for up to 23 to 24 cows. To record methane emissions of 68 cows during ad libitum feeding, 23 cows had access to one GreenFeed unit during the $70 \mathrm{~d}$. Half of the remaining 45 cows had access to the second GreenFeed unit during the first $5 \mathrm{wk}$ of those $70 \mathrm{~d}$ and the other half had access to the second GreenFeed unit during the following 5 wk. During feed restriction, because the number of cows was reduced to 30 , they all had a permanent access to a GreenFeed unit.

\section{Outlier Detection}

Outlier detection was applied to all measured phenotypes to remove abnormal data that are not biologically explainable. This step is important because any abnormal data that are not removed and used to estimate feed efficiency may end as model errors, and therefore in RFI. For milk production and composition, no abnormal data were detected (no days with values of 0 or higher than $100 \mathrm{~g} / \mathrm{kg}$ for milk fat or milk protein after 30 DIM).

For DMI and BW, all data associated with a value of 0 were discarded because a zero value was not bio- 
logically meaningful. The data were smoothed, based on data observation, using $40 \%$ for DMI and $20 \%$ for BW closest-in-time data to fit local regression (Loess function in R; R Core Team, 2018). A data point was considered an outlier if it was outside the range of 2 times (for BW) and 2.75 times (for DMI) the standard deviation of the closest neighbors around the value of the smoothed data (based on data observation). Outlier data were removed from the data set. Because BW had more variable day-to-day data, the 3 steps from smoothing to outlier detection were rerun until the smoothed curve did not differ significantly from the previous smoothed curve. Outliers data represented on average $4.8 \%( \pm 3.6 \%)$ of $\mathrm{BW}$ data and $1.0 \%( \pm 0.8 \%)$ of DMI data.

For methane and carbon dioxide data, a few data points had to be removed because they were abnormal. To do so, a least rectangles regression of carbon dioxide against methane emission was fitted to detect methane outliers using the least.rect function of package RVAideMemoire (Hervé, 2018) in R (R Core Team, 2018). Data outside the range of 3 standard deviations of the residuals around the regression line were considered as outliers and were removed. On average $0.6 \%$ $(\mathrm{SD}=1.7 \%)$ of the initial data were removed per cow for being outliers. Methane data were then averaged per experimental period and per cow. Methane data showed neither a significant effect of average visit time $(P=0.39$; on average visit time was $1129 \mathrm{~h} \pm 53 \mathrm{~min})$ nor an effect of number of visits $(P=0.54$; on average $2.5 \pm 0.46$ visits/cow per d) on methane produced per experimental period.

\section{Variables Calculation to Estimate Feed Efficiency}

Estimation of feed efficiency requires DMI data and all energy outputs or energy inputs to be considered for a lactating dairy cow. Energy outputs gather net energy in milk, energy required for maintenance, energy gained as adipose tissue, and energy required for gestation. Other energy inputs include adipose tissue mobilization.

Net energy in milk was calculated according to the following equation (Faverdin et al., 2010):

$$
\begin{aligned}
& \text { NEMilk }(\mathrm{UFL} / \mathrm{d})=\text { MilkProd } \times[0.44+0.0055 \\
& \times(\mathrm{MFC}-40)+0.0033 \times(\mathrm{MPC}-31)]
\end{aligned}
$$

where MilkProd is the milk production in kilograms per day, MFC is the milk fat concentration in grams per kilogram, and MPC is the milk protein concentration in grams per kilogram.
Gestation requirement were estimated with the following equation defined by Faverdin et al. (2010):

$$
\begin{gathered}
\text { gestation }(\mathrm{UFL} / \mathrm{d})= \\
0.00072 \times \text { BWbirth } \times \exp ^{0.116 \times \text { GestWeek }},
\end{gathered}
$$

where BWbirth is calf's weight at birth and assumed to be $40 \mathrm{~kg}$, and GestWeek is the week of gestation.

Body weight data used, after outliers removal, were smoothed with a LOESS using the $15 \%$ closest-in-time data, to better reflect change in maintenance and not to be sensitive to daily gutfill change. Monthly BCS data were filled to get daily BCS using a cubic Spline with the function smooth.spline in $\mathrm{R}$ ( $\mathrm{R}$ Core Team, 2018) using each scoring day as a knot. Maintenance requirements were estimated with the metabolic $\mathrm{BW}$, using the smoothed BW data, and calculated as $\mathrm{BW}^{0.75}$. Energy gained and energy mobilized as body reserves were estimated as the day-to-day change in smoothed BW. If the change was positive, it was attributed to body reserves gain, and body reserves loss was null. Conversely, if the change was negative, it was attributed to body reserves mobilization, and body reserves gain was null. Both BW gain and BW loss were constructed to be positive variables. Both $\mathrm{BW}$ gain and BW loss were multiplied by daily BCS to account for body reserves differences within a given BW, resulting in the variables BWlossBCS and BWgainBCS.

\section{Estimation of Efficiencies}

Estimation of Feed Efficiency to Define Feed Restriction Levels. Feed efficiency was estimated for the 68 cows with the RFI, defined as the difference between observed DMI and expected DMI during the $70 \mathrm{~d}$ of data kept during ad libitum feeding. Expected DMI was estimated with a linear regression predicting DMI as follows:

$$
\begin{aligned}
& \text { DMI }(\mathrm{kg} / \mathrm{d})=\mu+\text { NEMilk }+\mathrm{BW}^{0.75}+\Delta \mathrm{BW} \\
& + \text { parity }+ \text { parity } \times \text { NEMilk }+ \text { parity } \times \mathrm{BW}^{0.75} \\
& + \text { parity } \times \Delta \mathrm{BW}+\varepsilon, \quad(\text { model }
\end{aligned}
$$

where NEMilk is the net energy in milk in UFL/d, $\mathrm{BW}^{0.75}$ is the metabolic $\mathrm{BW}, \Delta \mathrm{BW}$ is the change in BW between the start and end of ad libitum feeding, parity is the fixed effect of parity (primiparous vs. multiparous), $\mu$ is the intercept, and $\varepsilon$ is the residual of the model, standing for RFI. All variables in the model, except $\Delta \mathrm{BW}$, were averaged over the $70 \mathrm{~d}$ of data used during ad libitum feeding. 
Estimation of Efficiencies During Ad Libitum Feeding and Feed Restriction Feeding. Precision feed restriction has been calculated based on RFI of cows during ad libitum feeding. Besides observing the change in feed efficiency due to feed restriction, it is also interesting to see if the same changes occurred for milk energy efficiency. Therefore, both feed and milk energy efficiencies have been estimated during ad libitum and feed restriction periods.

Feed efficiency was estimated as the RFI with the method developed in a previous paper (Fischer et al., 2018b). Briefly, instead of being estimated as the residual of the multiple linear regression estimating observed DMI with the main energy outputs and inputs, RFI was defined as the repeatable part of model residuals. To do so, each experimental period was subdivided in segments of around $14 \mathrm{~d}$ to have repeated measures for each cow within experimental period. This model includes a repeated effect of period segment for each cow and a random effect of cow on the intercept. Feed efficiency is then defined as the random part of the intercept (randomRFI). Applied to the current study, randomRFI was defined as the random intercept of the mixed model 2 below. The initial model included net energy in milk, metabolic BW, BWlossBCS, BWgainBCS, gestation requirement, BCS, their interaction with parity and period, and the fixed effect of period segment nested within period. Only significant $(P \leq$ 0.05 ) interactions and variables were kept in the model. Both random and repeated effects were grouped within feeding period. The variables were averaged per segment of $14 \mathrm{~d}$, resulting in 5 repetitions in ad libitum feeding period and 5 repetitions during feed restriction period.

$$
\begin{gathered}
\text { DMI }(\mathrm{kg} / \mathrm{d})=\left(\mu+\mu_{\text {cow }}\right) \text { NEMilk }+\mathrm{BW}^{0.75} \\
+ \text { BWlossBCS }+ \text { BWgainBCS }+ \text { parity }+ \text { feedinglevel } \\
+ \text { parity } \times \text { BWlossBCS }+ \text { parity } \times \text { BWgainBCS } \\
+ \text { feedinglevel } \times \text { BWlossBCS } \\
\quad+\text { segment } \mid \text { feedinglevel }+\varepsilon, \quad(\text { model } 2)
\end{gathered}
$$

where NEMilk is the net energy in milk in UFL/d, $\mathrm{BW}^{0.75}$ is the metabolic $\mathrm{BW}$ in $\mathrm{kg}^{0.75}$, gestation is the gestation requirement in UFL/d, parity is the fixed effect of parity, feedinglevel is the fixed effect of feeding level (ad libitum vs. restricted), segment|feedinglevel is the fixed effect of period segment nested within feeding level, parity $\times$ BWlossBCS is the interaction between BWlossBCS and parity, parity $\times$ BWgainBCS is the interaction between parity and BWgainBCS, feedinglevel $\times$ BWlossBCS the interaction between feeding level and BWlossBCS, $\mu$ is the fixed intercept, $\mu_{\text {cow }}$ is the random part of the intercept, and $\varepsilon$ is the error. Feed efficiency, called randomRFI, is defined as $\mu_{\text {cow }}$ in model 2.

Milk energy efficiency was estimated with the same methodology than feed efficiency and was called random residual milk energy (RandomRME). RandomRME was defined as the random intercept of model 3 below. The initial model included DMI, metabolic BW, BWlossBCS, BWgainBCS, gestation requirement, BCS, their interaction with parity and period, and the fixed effect of period segment nested within period. Only significant $(P \leq 0.05)$ interactions and variables were kept in the model. Both random and repeated effects were grouped within feeding period.

$$
\begin{aligned}
& \text { NEMilk }(\mathrm{UFL} / \mathrm{d})=\left(\mu+\mu_{\text {cow }}\right)+\mathrm{DMI}+\mathrm{BW}^{0.75} \\
& + \text { BWlossBCS }+ \text { gestation }+ \text { parity }+ \text { feedinglevel } \\
& + \text { parity } \times \text { gestation }+ \text { feedinglevel } \times \text { BWlossBCS } \\
& + \text { feedinglevel } \times \text { gestation }+ \text { feedinglevel } \times \mathrm{BW}^{0.75} \\
& + \text { feedinglevel } \times \text { DMI }+ \text { segment } \mid \text { feedinglevel }+\varepsilon,
\end{aligned}
$$

(model 3)

Milk energy efficiency, called randomRME, is defined as $\mu_{\text {cow }}$ in model 3 .

Milk efficiency was also expressed as the ratio between average ECM and average DMI within experimental period. ECM was calculated as follows according to Faverdin et al. (2010), to get milk production equivalent to a milk with a protein concentration of $3.1 \%$ and fat concentration of $4 \%$ :

$$
\operatorname{ECM}(\mathrm{kg} / \mathrm{d})=\text { NEMilk/0.44. }
$$

where NEMilk is in UFL per day.

\section{Statistical Analyses}

Objective of the study is to analyze if precision feed restriction improved feed efficiency without compromising performance. To answer this question, an analysis of covariance was fitted to test if the change in efficiency between feed restriction and ad libitum feeding was significantly different between the least and the most efficient cows for a given level of feed restriction. Feed restriction level has been centered within feed efficiency group to correct for the feed restriction level difference between the most and the least efficient cows.

Both feed and milk energy efficiency indicators were standardized within experimental period to make a given indicator comparable across periods. The change in efficiency was calculated for the 2 standardized in- 
dicators as the difference between value of an indicator during feed restriction and its value during ad libitum feeding. In the same way, the change in performance variables (milk production, BCS, BW loss, BW gain, BW, methane emission) and DMI were estimated as the difference between feed restriction and ad libitum feeding. Each of efficiency and performance variables underwent the following analysis of covariance to analyze if feed restriction changed efficiency without compromising performance:

$$
\begin{gathered}
\mathrm{Y}_{\text {Restrict }}-\mathrm{Y}_{\text {adlibitum }}=\left(\mathrm{DMI}_{\text {Restrict }}-\mathrm{DMI}_{\text {adlibitum }}\right) \\
+ \text { EfficiencyGroup }+ \text { EfficiencyGroup } \\
\times\left(\mathrm{DMI}_{\text {Restrict }}-\mathrm{DMI}_{\text {adlibitum }}\right)+\varepsilon
\end{gathered}
$$

where $\mathrm{Y}$ is either a performance indicator or a standardized efficiency indicator, EfficiencyGroup is the fixed effect of feed efficiency group (most vs. least efficient), $\left(\mathrm{DMI}_{\text {Restrict }}-\mathrm{DMI}_{\text {adlibitum }}\right)$ is the covariable of change in DMI between the 2 experimental periods centered within efficiency group, EfficiencyGroup $\times$ $\left(\mathrm{DMI}_{\text {Restrict }}-\mathrm{DMI}_{\text {adlibitum }}\right)$ is the interaction between change in DMI and feed efficiency group, and $\varepsilon$ is the residual; "restrict" stands for the value of the variable during feed restriction and "adlibitum" stands for the value of the variable during ad libitum feeding.

Analysis of variance combined with estimation of least squares means were adjusted during ad libitum feeding period and during feed restriction period to test significance of the difference between the most and least feed efficient cows within experimental period for the 2 efficiency indicators, DMI, performance, and methane emissions.

All analysis of covariance and ANOVA were performed with the Anova function in package car (Fox and Weisberg, 2011) and the least squares means were performed with lsmeans function of package lsmeans (Lenth, 2016) in R (R Core Team, 2018). All mixed models were performed with the Mixed procedure in SAS software (version 9.4, SAS Institute Inc., Cary, NC) with a repeated effect of period segment characterized with a first-order heterogeneous autoregressive variance-covariance matrix. Linear regressions were performed with $\mathrm{lm}$ function in R (R Core Team, 2018).

\section{RESULTS}

\section{Performance, Intake, Efficiencies, and Methane Emission Differences Between Efficiency Groups During Ad Libitum Feeding}

Intake and Efficiency Differences. The 2 efficiency groups differed significantly in DMI during ad libitum feeding. The most efficient cows ate 20.1 $\mathrm{kg}$ of $\mathrm{DM} / \mathrm{d}$, which was on average $2.6 \mathrm{~kg}$ of $\mathrm{DM} / \mathrm{d}$ less than the least efficient cows (Table 2). Within the same performance level, as shown by the difference in randomRFI, the most efficient cows ate 1.37 $\mathrm{kg}$ of $\mathrm{DM} / \mathrm{d}$ less than the least efficient cows (Table 2). Within the same performance level and DMI, as shown by the difference in randomRME, the most efficient cows produced $0.96 \mathrm{UFL} / \mathrm{d}$ more net energy in milk than the least efficient cows (Table 2). The most efficient cows produced $1.52 \mathrm{~kg}$ of $\mathrm{ECM} / \mathrm{kg}$ of DMI, which was $0.15 \mathrm{~kg}$ of ECM more per $\mathrm{kg}$ of DMI than the least efficient cows (Table 2). The feed that could have been saved during ad libitum, thanks to precision feed restriction, would have been on average $1.4 \mathrm{~kg}$ of $\mathrm{DM} / \mathrm{d}$ per cow, as defined by the difference between RFI of the 24 feed restricted cows and RFI of the top $10 \%$ most efficient cows during ad libitum feeding. This difference in $1.4 \mathrm{~kg}$ of $\mathrm{DM} / \mathrm{d} / \mathrm{cow}$ represented $6.5 \%$ of average DMI of the 24 feed restricted cows during ad libitum feeding.

Performance Differences. The least efficient cows produced the same amount of milk $(P=0.76)$ and ECM $(P=0.81)$, but with slightly higher concentration and production of milk solids compared with the most efficient cows (Table 2). Despite a tendency toward higher milk fat concentrations for the least efficient cows $(P=0.09)$, net energy exported in milk did not differ between the groups with on average $13.6 \mathrm{UFL} / \mathrm{d}$ being exported in milk (Table 2).

Body reserves change, as measured by $\mathrm{BW}$ change, differed between the 2 groups with a higher BW loss $(P$ $<0.01)$ and a lower BW gain $(P=0.08)$ for the most efficient cows. The most efficient cows lost $0.10 \mathrm{~kg} / \mathrm{d}$, which is $0.07 \mathrm{~kg} / \mathrm{d}$ more than the least efficient cows, and gained $0.31 \mathrm{~kg} / \mathrm{d}$, which is $0.12 \mathrm{~kg} / \mathrm{d}$ less than the least efficient cows (Table 2). Maintenance variables were similar for both groups $(P=0.41$ for $\mathrm{BW}$ and $P$ $=0.11$ for BCS, Table 2) with an average BW of 648.5 $\mathrm{kg}$ and an average BCS of 1.98.

Methane Emission Differences. Daily methane emissions did not significantly differ between the most and least efficient cows $(P=0.41$, Table 2$)$, with an average methane emission of $494 \mathrm{~g} / \mathrm{d}$. Given this result and a significantly higher DMI for the least efficient cows, we observed that the most efficient cows emitted significantly more methane per DMI than the least efficient cows $(P=0.04$, Table 2$)$, with $24.2 \mathrm{~g}$ of methane being emitted per $\mathrm{kg}$ of DMI by the most efficient cows and $22.2 \mathrm{~g} / \mathrm{kg}$ of DMI by the least efficient cows. No significant difference was observed between the 2 groups when methane was expressed per kilogram of milk produced, per kilogram of ECM, or per kilogram of BW (Table 2). 
Fischer et al.: PRECISION FEED RESTRICTION IMPROVES EFFICIENCY

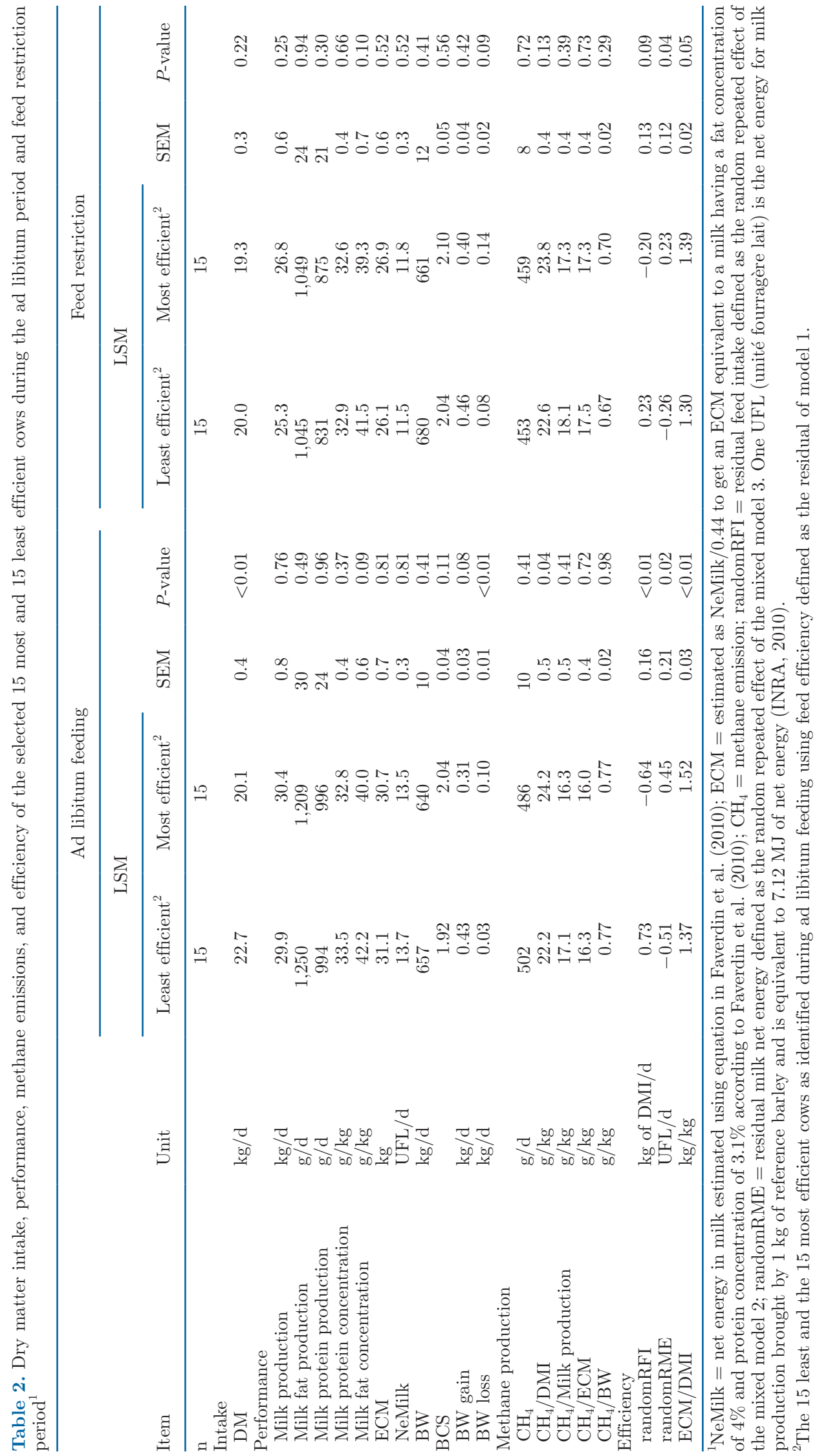


Table 3. Change in DMI, performance, methane production, and efficiency between ad libitum and feed restriction between efficiency groups (least and most efficient cows) ${ }^{1}$

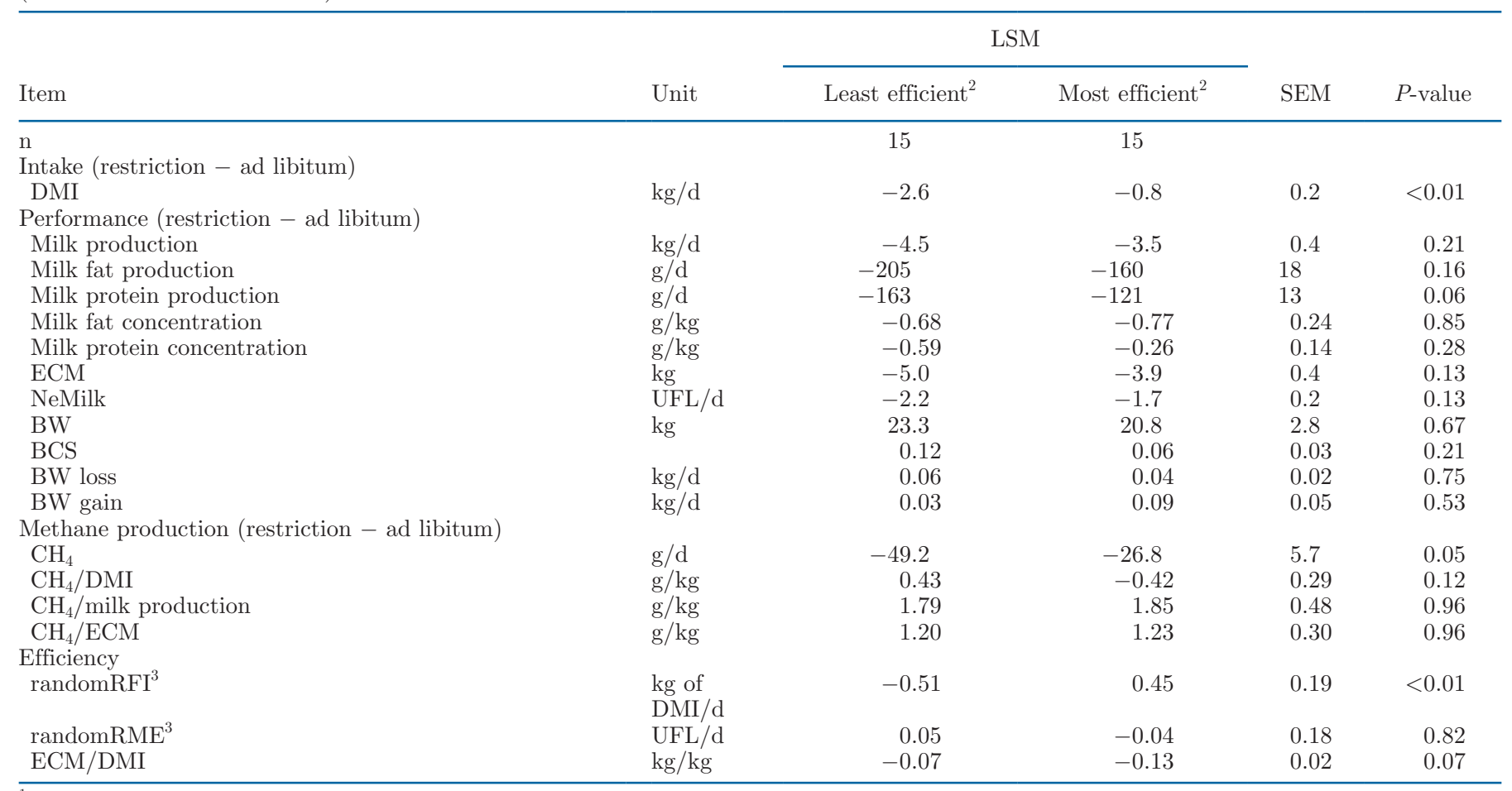

${ }^{1}$ For performance and methane production variables, LSM were estimated on an analysis of covariance of the change explained by change in intake centered within efficiency group. NeMilk = net energy in milk estimated using equation in Faverdin et al. (2010); ECM = estimated as NeMilk/0.44 to get an ECM equivalent to a milk having a fat concentration of $4 \%$ and protein concentration of $3.1 \%$ according to Faverdin et al. (2010); $\mathrm{CH}_{4}=$ methane production; randomRFI = residual feed intake defined as the random repeated effect of the mixed model 2; randomRME $=$ residual milk net energy defined as the random repeated effect of the mixed model 3. One UFL is the net energy for milk production brought by $1 \mathrm{~kg}$ of reference barley and is equivalent to 7.12 MJ of net energy (INRA, 2010).

${ }^{2}$ The 15 least and the 15 most efficient cows as identified during ad libitum feeding using feed efficiency defined as the residual of model 1.

${ }^{3}$ These variables have been standardized within period before calculating the change across periods.

\section{Effect of Precision Feed Restriction on Intake and Performance}

As expected by the experimental design, DMI did not significantly differ between the 2 efficiency groups during feed restriction $(P=0.22$, Table 2$)$. The least efficient cows ate $2.6 \mathrm{~kg}$ of $\mathrm{DM} / \mathrm{d}$ less during feed restriction, which is, as expected, significantly higher $(P$ $<0.01$ ) than the DMI decrease observed for the most efficient cows $(-0.8 \mathrm{~kg}$ of DM/d, Table 3$)$. Among the 6 cows used as reference for feed restriction calculation, 2 cows appeared feed restricted because they had a lower DMI during feed restriction period (Figure 1D). During precision feed restriction, the 2 efficiency groups tended to differ for randomRFI $(P=0.09$, Table 2$)$ and differed significantly for randomRME $(P=0.04$, Table 2$)$.

All other variables, were not different between the 2 groups during feed restriction (Table 2). In spite of a more important feed restriction for the least efficient cows, milk-associated variables decreased similarly for the most and the least efficient cows $(P \geq 0.06$, Table
3) with an average decrease of net energy in milk of $1.95 \mathrm{UFL} / \mathrm{d}$. Only the change in milk protein production tended to be significantly different between the 2 groups $(P=0.06)$ with a decrease of $163 \mathrm{~g} / \mathrm{d}$ for the least efficient cows and $121 \mathrm{~g} / \mathrm{d}$ for the most efficient cows (Table 3). The change in maintenance associated variables (BW and BCS) and the change in body reserves change variables (BW loss and $\mathrm{BW}$ gain) associated with precision feed restriction were not significantly different between the most and the least efficient cows (Table 3).

Due to feed restriction, methane emissions decreased significantly more for the least efficient cows with a decrease of $49.2 \mathrm{~g} / \mathrm{d}$ compared with $26.8 \mathrm{~g} / \mathrm{d}$ for the most efficient cows $(P=0.05$, Table 3$)$. The change in methane yield per intake or in methane yield per milk yield due to feed restriction did not significantly differ between the 2 efficiency groups: average methane yield per kilogram of DMI was maintained and average methane yield per kilogram of milk increased by 1.82 $\mathrm{g}$ of $\mathrm{CH}_{4} / \mathrm{kg}$ of milk (1.22 $\mathrm{g}$ of $\mathrm{CH}_{4} / \mathrm{kg}$ of ECM). Even 
if the change in methane yield did not differ between the 2 groups, the relationship between change in methane yield per kilogram of DMI and change in DMI was negative, and showed that the more restricted the cow was, the more her methane yield per kilogram of DMI increased $(\mathrm{r}=-0.44, P=0.02$, Figure 2).

\section{Effect of Precision Feed Restriction on Feed Efficiency and Milk Energy Efficiency}

Precision feed restriction reduced the variability of both feed and milk energy efficiencies. Feed efficiency, as defined with randomRFI, had a standard deviation of $0.87 \mathrm{~kg}$ of $\mathrm{DM} / \mathrm{d}$ during ad libitum feeding, which was divided by 1.3 with feed restriction to end up with a standard deviation of $0.69 \mathrm{~kg}$ of $\mathrm{DM} / \mathrm{d}$. Milk energy efficiency, as defined with randomRME, had a standard deviation of $1.14 \mathrm{UFL} / \mathrm{d}$ during ad libitum feeding, which was divided by 1.8 with feed restriction to end up with a standard deviation of $0.65 \mathrm{UFL} / \mathrm{d}$. Associated coefficients of variation, which compare efficiency standard deviation to DMI average for randomRFI and to net energy in milk average for randomRME, decreased from 4.1 to $3.5 \%$ for randomRFI, and from 8.4 to $5.5 \%$ for randomRME.

Both efficiency indicators estimated during ad libitum feeding correlated positively with their homologues estimated during feed restriction. Pearson correlation between efficiency indicator estimated during ad libitum feeding and the same indicator estimated during feed restriction was $0.46(P=0.01)$ for randomRFI and $0.49(P<0.01)$ for randomRME (Figure 3). Even if these correlations within efficiency indicator across periods were positive, it is worth noting that the differences in efficiency between the most and least efficient cows, as identified during ad libitum feeding, are smaller during feed restriction (Figure 3 ). In fact, the 2 feed efficiency groups did, as expected, not overlap for feed efficiency and slightly overlapped for milk energy efficiency during ad libitum feeding, whereas they overlapped during feed restriction for both feed and milk energy efficiencies (Figure 3).

After standardizing each efficiency indicator within experimental period, the least efficient cows identified during ad libitum feeding gained $0.51 \mathrm{~kg}$ of $\mathrm{DM} / \mathrm{d}$ feed efficiency and 0.05 UFL/d milk energy efficiency (Table 3 ). The least efficient cows identified during ad libitum period gained significantly more feed efficiency than the most efficient cows lost feed efficiency $(P<0.01)$, but did not gain more milk energy efficiency than the most efficient cows $(P=0.82$, Table 3$)$. The most efficient cows lost twice as much ECM per kg of DMI $(P=0.07$, Table 3) due to precision feed restriction than the least efficient cows who decreased their ECM/DMI ratio by $0.07 \mathrm{~kg}$ of $\mathrm{ECM} / \mathrm{kg}$ of DMI, even if feed restriction was lower for the most efficient cows (Table 3).

\section{DISCUSSION}

The strategy was to restrict the 15 most and 15 least feed efficient cows at the feeding level of the $10 \%$ most efficient cows, given similar productions levels, to improve feed efficiency. Precision feed restriction was mostly achieved because feed restriction was more important for the least efficient dairy cows with a restriction at $88.1 \%$ of ad libitum intake for the 15 least efficient cows and $96 \%$ of ad libitum intake for the 15 most efficient cows. The top $10 \%$ of the most feed efficient cows $(\mathrm{n}=6)$ was supposed not feed restricted. However, 2 cows appeared feed restricted because they had a lower DMI. In fact, these 2 cows left more refusals than during ad libitum period and should not be considered as feed restricted. Restricting the cows to the feeding level of the $10 \%$ most efficient cows can be seen as precision feeding because each cow was restricted according to its own overconsumption of feed compared with the consumption of the $10 \%(\mathrm{n}=6)$ most efficient cows, given similar performance.

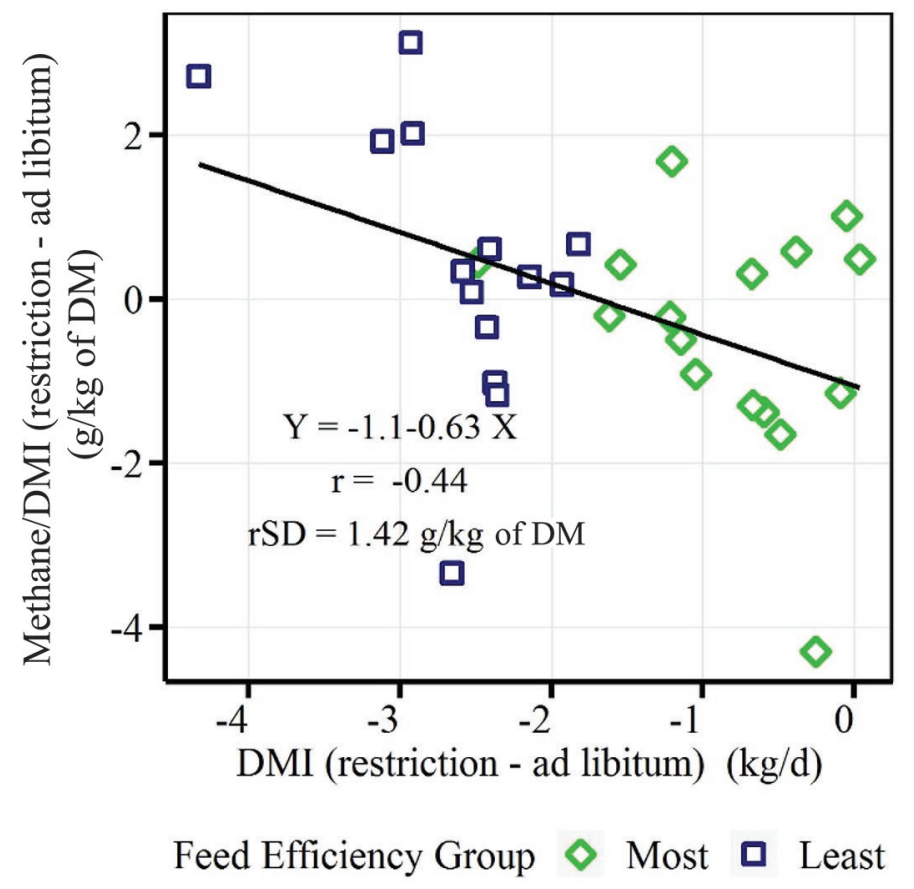

Figure 2. Relationship between the change in methane yield per kilogram of DMI and the change in DMI between restriction and ad libitum periods $(\mathrm{n}=30$ cows). The regression fitted with the LSM is shown by a solid black line; rSD = residual standard deviation. 

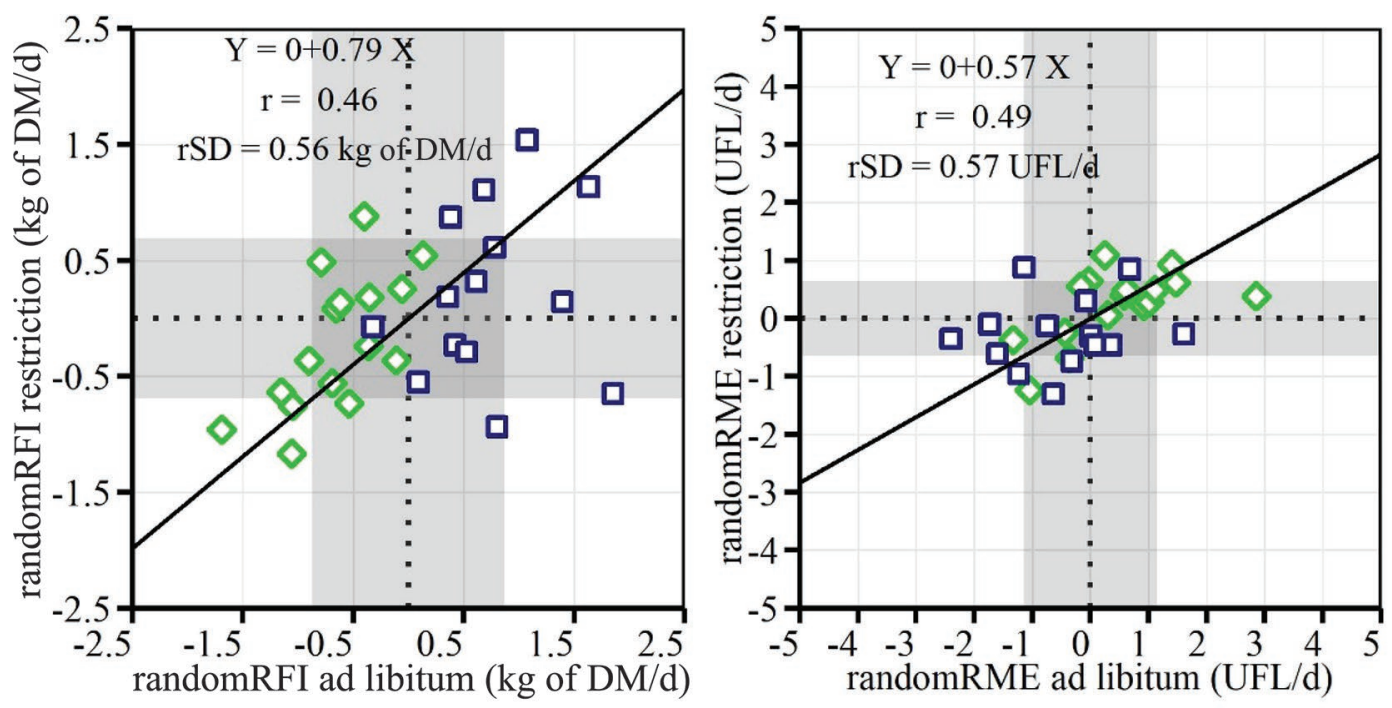

Feed Efficiency Group $\diamond$ Most efficient $\square$ Least efficient

Figure 3. Relationship between feed or milk net energy efficiencies estimated during ad libitum feeding with the same indicator estimated during feed restriction $(\mathrm{n}=30 \mathrm{cows})$. For each graph, the regression fitted with the least rectangles means is shown by a solid black line, with its equation, correlation coefficient $(\mathrm{r})$ and residual standard deviation (rSD). Each gray rectangle shows the interval of average \pm 1 SD within each period. randomRFI $=$ residual feed intake defined as the random repeated effect of the mixed model 2 ; randomRME $=$ residual milk net energy defined as the random repeated effect of the mixed model 3. One unité fourragère lait (UFL) is the net energy for milk production brought by $1 \mathrm{~kg}$ of reference barley and is equivalent to $7.12 \mathrm{MJ}$ of net energy (INRA, 2010).

\section{Feeding Less Efficient Cows at Feeding Level of the Most Efficient Cows Improves Their Feed and Milk Efficiencies}

Precision feed restriction improved feed efficiency and milk energy efficiency of cows. Precision feed restriction reduced the differences in feed and milk energy efficiencies between cows. Indeed, variability of randomRFI and variability of randomRME have noticeably been reduced with precision feed restriction, to end up with a standard deviation of $0.69 \mathrm{~kg}$ of $\mathrm{DM} / \mathrm{d}$ for randomRFI and $0.65 \mathrm{UFL} / \mathrm{d}$ for randomRME. Those standard deviations are small compared with the average of DMI when considering randomRFI and compared with average net energy in milk when considering randomRME: coefficients of variation were divided by 1.2 for randomRFI and by 1.5 for randomRME with feed restriction. The ratio between ECM and DMI, commonly used as a milk efficiency indicator, decreased for both efficiency groups, and decreased slightly less for the least efficient cows. However, this decrease may rather reflect an effect of higher lactation stages, and less an effect of precision feed restriction. Indeed, more energy is used for body reserves accretion and less for milk production toward late lactation stages, leading to reduced ECM per DMI. This result highlights the limits of ECM/ DMI to be used as an indicator of overall feed or milk energy efficiencies in dairy cows: it only accounts for milk as energy output whereas other outputs are essential for a dairy cow to produce milk, such as body reserves mobilization and gain.

This reduction in feed efficiency variability, due to precision feed restriction, could be explained either by a gain in total-tract digestibility or by a shift in energy allocation between functions not included in the model or by an increased efficiency of energy output or input already included in the model. When cows are feed restricted, total-tract digestibility, and especially fiber digestibility in the rumen, increases (Volden, 1999; Gabel et al., 2003; Santana et al., 2019). This increase in digestibility can be due to a decrease in fractional passage rate out of the rumen because feeding levels are reduced when animals are feed restricted. This reduction in passage rate can lead to an increased mean retention time of feed in the rumen (Volden, 1999; Dias et al., 2011), and consequently a higher chance to complete digestion of fibers. Having less feed transiting through the digestive tract may lead to more digestion end products per kilogram of DMI, which should increase partial efficiency to produce milk or maintenance (Sauvant et al., 2018). Each percent increase in DMI (as per kg of BW) decreases OM digestibility by $2.74 \%$ (Sauvant et al., 2018). Given that our precision feed restriction decreased DMI by $0.52 \%$ (as per $\mathrm{kg}$ of 
BW) for the least efficient cows and by $0.22 \%$ for the most efficient cows, digestibility may have increased by 1.42 units for the least and by 0.60 unit for the most efficient cows. This difference in digestibility gain of 0.82 unit between the least and the most efficient cows could represent a gain in digested feed of $1.17 \%(0.82 / 70$ for a diet OM digestibility of $70 \%$ ). With an initial DMI of $22.7 \mathrm{~kg}$ of $\mathrm{DM} / \mathrm{d}$ for the least efficient cows during ad libitum feeding, the least efficient cows must have digested $0.27 \mathrm{~kg}$ of $\mathrm{DM} / \mathrm{d}(22.7 \times 0.0117)$ more feed compared with ad libitum feeding thanks to the gain in digestibility. This gain in digested feed represents $27 \%$ of the $0.94 \mathrm{~kg}$ of DM/d reduction in randomRFI difference between the most and the least efficient cows with precision feed restriction. Based on the Sauvant et al. (2018) equation, gain in digestibility may only explain $27 \%$ of the $0.94 \mathrm{~kg}$ of DM/d gain in feed efficiency; the remaining $73 \%$ of the $0.94 \mathrm{~kg}$ of $\mathrm{DM} / \mathrm{d}$ gain may be due to different mechanisms or to an underestimation of the effect of feeding level change on digestibility.

Indirectly, by going further in the digestion process in the rumen, especially in fiber digestion, a higher digestion should increase methane emissions per kilogram of DMI (Moibi et al., 2004; Lima et al., 2016). This hypothesis is supported by the negative correlation observed between RFI and digestibility (Potts et al., 2017; Fischer et al., 2018a; Oliveira et al., 2018), and was indirectly observed in our study because the more feed restricted the cow was, the more she increased her methane emission per kilogram of DMI. In a previous study where cows were fed ad libitum with a diet similar to the current study, lower RFI (higher feed efficiency) stood for higher DM digestibility (Fischer et al., 2018a). However, the literature lacks consensus on the positive relationship between feed efficiency and totaltract digestibility, which depends on the diet (Oliveira et al., 2016; Potts et al., 2017). This lack of consensus justifies more studies to better understand the relation between feed efficiency and digestibility.

\section{No Higher Performance Reduction for Feed- Restricted Least Efficient Cows}

Previous paragraph showed an improvement in feed and milk energy efficiencies with precision feed restriction. Besides the hypothesis of digestibility gain, another hypothesis would argue that the cows compensated lower feed intake by reducing their performance or by using energy stored as body reserves.

The greater feed restriction of less efficient cows did not impair their performance more than the most efficient cows, who were less feed restricted. This result combined with improved feed efficiency suggest that cows are less efficient because they overconsume feed given their energy requirements. Indeed, changes in milk performance, BW, BCS, and body reserves change due to precision feed restriction were not significantly different between the least efficient cows and the most efficient cows for a similar level of feed restriction. If cows would have compensated reduction in feed intake by mobilizing more energy stored in their body reserves, change in BW loss between ad libitum and feed restriction would have been significantly higher for the least efficient cows than the most efficient cows. This was not observed in the current study. One could argue that the most efficient cows lost significantly more BW during ad libitum feeding than the least efficient cows, and could therefore be concerned about resiliency of feed efficiency definition. This difference is small and does not mean that the most efficient cows will be cows mobilizing more body reserves over the full lactation. Indeed, the least efficient cows lost $0.1 \mathrm{~kg} / \mathrm{d}$ over the $72 \mathrm{~d}$ of ad libitum monitoring, equivalent to $7.2 \mathrm{~kg}$, which was $5.1 \mathrm{~kg}$ more than the least efficient cows. Moreover, by definition RFI is independent from all variables included in the model used to estimate it (i.e., independent from BW change). This independence does not mean that 2 extreme groups (one most efficient and one least efficient) will be similar for the variables included in the model, and may explain why the 2 efficiency groups in our study differed in BW loss during ad libitum feeding.

As expected, feed restriction reduced milk production and milk content of both efficiency groups, as shown by the negative change in milk production, milk content, and net energy exported in milk with feed restriction. This decrease in milk performance due to feed restriction is widely explained and accepted in the literature (Abdelatty et al., 2017; Herve et al., 2019). Taken all together, the results suggest that improving feed efficiency by precision feed restriction is possible without impairing performance of dairy cows, while improving their milk energy efficiency.

\section{Feed Efficiency and Methane Emissions}

Increasing feed efficiency of dairy cows will not necessarily decrease methane emissions. Despite a slightly lower, but not significant, methane emission per day, the most efficient dairy cows are mainly characterized by a significantly higher methane yield per kilogram of DMI. This observation agrees with studies in growing cattle (Fitzsimons et al., 2013; McDonnell et al., 2016; Flay et al., 2019). A higher methane yield per kilogram of DMI for most efficient cattle is observed more consistently in the literature than the relationship 
between feed efficiency and methane emission per day. It could also indicate that part of inefficiency can be due to a lower diet digestibility in the rumen, which could be associated with this lower methane yield per kilogram of DMI. Some studies showed a lower methane emission for the most efficient cattle (Nkrumah et al., 2006; Hegarty et al., 2007; Fitzsimons et al., 2013), and others showed no difference between the most and least efficient cattle (McDonnell et al., 2016; Oliveira et al., 2016; Flay et al., 2019). The lack of consensus about the relationship between methane emissions per day and feed efficiency is hard to explain, and maybe related to differences in experimental conditions, such as method used to measure methane emission, feeding level, or level of grains in the diet. Studies with diets rich in grains tend to observe a lower methane emission per day for the most efficient cows (Nkrumah et al., 2006; Hegarty et al., 2007; Jones et al., 2011).

\section{Implications for Field Application}

Results of the current paper suggest that if the 24 cows, who were less efficient than the top $10 \%$ most efficient cows during ad libitum feeding, would have been fed at the feeding level of the top $10 \%$ most efficient cows, they would have consumed $1.4 \mathrm{~kg}$ of $\mathrm{DM} /$ cow per d less $(6.5 \%$ less $)$ for similar performance levels. When applied to the whole herd $(\mathrm{n}=68)$, precision feed restriction would have saved $1.5 \mathrm{~kg}$ of $\mathrm{DM} / \mathrm{d}$ feed (6.7\% of DMI) for similar performance levels.

Precision feed restriction was performed at end of lactation, when requirements for lactation function are the lowest. Current results should be validated at earlier lactation stages to be sure that precision feed restriction does not impair performance more than it saves feed. Application of precision feed restriction will only be available in field conditions once individual feed intake recording systems or feed efficiency monitoring systems, and individual feed dispensing systems are available on farm. Impediments to feed efficiency monitoring are either accessibility to individual feed intake monitoring or accessibility to an indirect indicator of feed efficiency. Feed intake may be accessible on farm in the near future, thanks to new technologies. Even if estimation of individual feed intake is progressing rapidly, its precision is still lacking, and gives more hope on the use of an indirect indicator of feed efficiency. The second option, estimating feed efficiency indirectly, is interesting, especially if we are able to identify an indicator of feed efficiency, which does not require individual feed intake measurements and is accessible on farm. More work needs to be done in this field.
Instead of restricting the total amount of diet, as done in the current paper, one can suggest to restrict the least efficient cows by restricting their access to concentrates, while keeping similar concentrations in diet energy and protein. Diet composition would change between the most and the least efficient cows, and will therefore make any feed efficiency estimation more complicated.

\section{CONCLUSIONS}

Precision feed restriction applied to less efficient dairy cows, so that they are fed at the feeding level of the $10 \%$ most efficient cows for similar performance, improved their feed efficiency and milk energy efficiency. Precision feed restriction significantly narrowed the differences between cows for feed and milk energy efficiencies. Precision feed restriction did not impair lactation, body reserves gain, and maintenance performance more for restricted cows than for the least restricted cows. Methane yields, expressed per kilogram of DMI, were higher for the most efficient cows. Precision feed restriction reduced daily methane emissions more for the least efficient cows than for the most efficient cows, primarily because the least efficient cows were more feed restricted than the most efficient cows. Reduction in methane emissions and improvement of efficiency without impairing cows performance suggest that part of feed inefficiency may come from overconsumption of feed, which leads to lower mean retention time of feed in the rumen and therefore to lower digestibility. Further research should therefore focus on better understanding of whether this improvement comes from a better digestibility in the rumen, especially fiber digestibility, from improving metabolic efficiencies, or both.

\section{ACKNOWLEDGMENTS}

The authors warmly thank technical staff and managers at the INRA Méjusseaume (France) research facility who helped manage this experiment, did a great job of precision monitoring, extracting, and preparing the data, and biologically clarifying abnormal data. We are also grateful to the national project Deffilait (Agence Nationale de la Recherche, Paris, France, ANR-15-CE20-0014) and APIS-GENE (Paris, France) for funding this research project. The authors declare that they have no conflicts of interest.

\section{REFERENCES}

Abdelatty, A. M., M. E. Iwaniuk, M. Garcia, K. M. Moyes, B. B. Teter, P. Delmonte, A. K. G. Kadegowda, M. A. Tony, F. F. Moha- 
mad, and R. A. Erdman. 2017. Effect of short-term feed restriction on temporal changes in milk components and mammary lipogenic gene expression in mid-lactation Holstein dairy cows. J. Dairy Sci. 100:4000-4013. https://doi.org/10.3168/jds.2016-11130.

Andre, G., P. B. M. Berentsen, G. Van Duinkerken, B. Engel, and A. Lansink. 2010. Economic potential of individual variation in milk yield response to concentrate intake of dairy cows. J. Agric. Sci. 148:263-276. https://doi.org/10.1017/s0021859610000134.

Bazin, S. 1984. Grille de notation de l'état d'engraissement des vaches Pie Noires. Institut Technique de l'élevage Bovin, Paris, France.

Ben Meir, Y. A., M. Nikbachat, Y. Portnik, S. Jacoby, H. Levit, D. Bikel, G. Adin, U. Moallem, J. Miron, S. J. Mabjeesh, and I. Halachmi. 2019. Dietary restriction improved feed efficiency of inefficient lactating cows. J. Dairy Sci. 102:8898-8906. https://doi.org/ 10.3168 /jds.2019-16321.

Colucci, P. E., L. E. Chase, and P. J. Van Soest. 1982. Feed intake, apparent diet digestibility, and rate of particulate passage in dairy cattle. J. Dairy Sci. 65:1445-1456. https://doi.org/10.3168/jds .S0022-0302(82)82367-9.

Dias, R. S., H. O. Patino, S. López, E. Prates, K. C. Swanson, and J. France. 2011. Relationships between chewing behavior, digestibility, and digesta passage kinetics in steers fed oat hay at restricted and ad libitum intakes. J. Anim. Sci. 89:1873-1880. https://doi .org/10.2527/jas.2010-3156.

European Commission. 2018. EU Dairy farms report based on 2016 FADN data. Page 185 in Agriculture and Rural Development. E. Commission, ed. European Commission Directorate-General for Agriculture and Rural Development. Accessed Sep. 19, 2019. https: //ec.europa.eu/agriculture/rica/pdf/Dairy_report_2016.pdf.

Faverdin, P., R. Delagarde, L. Delaby, and F. Meschy. 2010. Alimentation des vaches laitières. Pages 23-58 in Alimentation des bovins, ovins et caprins. Besoins des animaux - Valeurs des aliments. INRA, ed. Quae, Versailles, France.

Fischer, A., R. Delagarde, and P. Faverdin. 2018a. Identification of biological traits associated with differences in residual energy intake among lactating Holstein cows. J. Dairy Sci. 101:4193-4211. https://doi.org/10.3168/jds.2017-12636.

Fischer, A., N. C. Friggens, D. P. Berry, and P. Faverdin. 2018b. Isolating the cow-specific part of residual energy intake in lactating dairy cows using random regressions. Animal 12:1396-1404. https: //doi.org/10.1017/S1751731117003214.

Fitzsimons, C., D. A. Kenny, M. H. Deighton, A. G. Fahey, and M. McGee. 2013. Methane emissions, body composition, and rumen fermentation traits of beef heifers differing in residual feed intake. J. Anim. Sci. 91:5789-5800. https://doi.org/10.2527/jas.2013 -6956 .

Flay, H. E., B. Kuhn-Sherlock, K. A. Macdonald, M. Camara, N. Lopez-Villalobos, D. J. Donaghy, and J. R. Roche. 2019. Hot topic: Selecting cattle for low residual feed intake did not affect daily methane production but increased methane yield. J. Dairy Sci. 102:2708-2713. https://doi.org/10.3168/jds.2018-15234.

Fox, J., and S. Weisberg. 2011. An $\{\mathrm{R}\}$ Companion to Applied Regression. 2nd ed. Sage, Thousand Oaks, CA.

Gabel, M., B. Pieper, K. Friedel, M. Radke, A. Hagemann, J. Voigt, and S. Kuhla. 2003. Influence of nutrition level on digestibility in high yielding cows and effects on energy evaluation systems. J. Dairy Sci. 86:3992-3998. https://doi.org/10.3168/jds.S0022 -0302(03) 74010-7.

Gonzalez-Recio, O., M. P. Coffey, and J. E. Pryce. 2014. On the value of the phenotypes in the genomic era. J. Dairy Sci. 97:7905-7915. https://doi.org/10.3168/jds.2014-8125.

Hardie, L. C., M. J. VandeHaar, R. J. Tempelman, K. A. Weigel, L. E. Armentano, G. R. Wiggans, R. F. Veerkamp, Y. de Haas, M. P. Coffey, E. E. Connor, M. D. Hanigan, C. Staples, Z. Wang, J. C. M. Dekkers, and D. M. Spurlock. 2017. The genetic and biological basis of feed efficiency in mid-lactation Holstein dairy cows. J. Dairy Sci. 100:9061-9075. https://doi.org/10.3168/jds.2017-12604.

Hegarty, R. S., J. P. Goopy, R. M. Herd, and B. McCorkell. 2007. Cattle selected for lower residual feed intake have reduced daily methane production. J. Anim. Sci. 85:1479-1486. https://doi.org/ 10.2527/jas.2006-236.
Herve, L., H. Quesnel, M. Veron, J. Portanguen, J. J. Gross, R. M. Bruckmaier, and M. Boutinaud. 2019. Milk yield loss in response to feed restriction is associated with mammary epithelial cell exfoliation in dairy cows. J. Dairy Sci. 102:2670-2685. https://doi.org/ $10.3168 /$ jds.2018-15398.

Hervé, M. 2018. RVAideMemoire: Testing and PLotting Procedures for Biostatistics. R package version 0.9-70 ed.

Hurley, A. M., N. Lopez-Villalobos, S. McParland, E. Lewis, E. Kennedy, M. O'Donovan, J. L. Burke, and D. P. Berry. 2018. Characteristics of feed efficiency within and across lactation in dairy cows and the effect of genetic selection. J. Dairy Sci. 101:1267-1280. https://doi.org/10.3168/jds.2017-12841.

Institut National de la Recherche Agronomique (INRA). 2010. Alimentation des bovins, ovins et caprins. Besoins des animaux - Valeurs des aliments: tables Inra 2007 mise à jour 2010. Page 311 in Alimentation des bovins, ovins et caprins. Besoins des animaux - Valeurs des aliments. INRA, ed. Quae, Versailles, France.

Jones, F. M., F. A. Phillips, T. Naylor, and N. B. Mercer. 2011. Methane emissions from grazing Angus beef cows selected for divergent residual feed intake. Anim. Feed Sci. Technol. 166-167:302-307. https://doi.org/10.1016/j.anifeedsci.2011.04.020.

Lenth, R. V. 2016. Least-Squares Means: The R Package lsmeans. J. Stat. Softw. 69:1-33. https://doi.org/10.18637/jss.v069.i01.

Li, B., B. Berglund, W. F. Fikse, J. Lassen, M. H. Lidauer, P. Mäntysaari, and P. Løvendahl. 2017. Neglect of lactation stage leads to naive assessment of residual feed intake in dairy cattle. J. Dairy Sci. 100:9076-9084. https://doi.org/10.3168/jds.2017-12775.

Lima, A. R. C., M. H. M. R. Fernandes, I. A. M. A. Teixeira, R. T. S. Frighetto, T. F. V. Bompadre, B. Biagioli, N. C. Meister, and K. T. Resende. 2016. Effects of feed restriction and forage:concentrate ratio on digestibility, methane emission, and energy utilization by goats. Rev. Bras. Zootec. 45:781-787. https://doi.org/10.1590/ s1806-92902016001200008.

McDonnell, R. P., K. J. Hart, T. M. Boland, A. K. Kelly, M. McGee, and D. A. Kenny. 2016. Effect of divergence in phenotypic residual feed intake on methane emissions, ruminal fermentation, and apparent whole-tract digestibility of beef heifers across three contrasting diets. J. Anim. Sci. 94:1179-1193. https://doi.org/10 $.2527 /$ jas.2015-0080.

Moibi, J., G. K. Murdoch, B. T. Li, H. Klooster, W. T. Dixon, E. K. Okine, and R. J. Christopherson. 2004. Methane production by beef steers as affected by feeding level, breed type and diet. Can. J. Anim. Sci. 84:777 (Abstr.) https://doi.org/10.4141/A04-abstracts.

Nkrumah, J. D., E. K. Okine, G. W. Mathison, K. Schmid, C. Li, J. A. Basarab, M. A. Price, Z. Wang, and S. S. Moore. 2006. Relationships of feedlot feed efficiency, performance, and feeding behavior with metabolic rate, methane production, and energy partitioning in beef cattle. J. Anim. Sci. 84:145-153. https://doi.org/10.2527/ $2006.841145 \mathrm{x}$

Oliveira, L. F., A. C. Ruggieri, R. H. Branco, O. L. Cota, R. C. Canesin, H. J. U. Costa, and M. E. Z. Mercadante. 2018. Feed efficiency and enteric methane production of Nellore cattle in the feedlot and on pasture. Anim. Prod. Sci. 58:886-893. https://doi.org/10 .1071/AN16303.

Pino, F., L. K. Mitchell, C. M. Jones, and A. J. Heinrichs. 2018. Comparison of diet digestibility, rumen fermentation, rumen rate of passage, and feed efficiency in dairy heifers fed ad-libitum versus precision diets with low and high quality forages. J. Appl. Anim. Res. 46:1296-1306. https://doi.org/10.1080/09712119.2018 .1498788 .

Potts, S. B., J. P. Boerman, A. L. Lock, M. S. Allen, and M. J. VandeHaar. 2017. Relationship between residual feed intake and digestibility for lactating Holstein cows fed high and low starch diets. J. Dairy Sci. 100:265-278. https://doi.org/10.3168/jds.2016-11079.

R Core Team. 2018. R: A language and environment for statistical computing. in R Foundation for Statistical Computing., Vienna, Austria.

Santana, P. F., V. R. Rocha Júnior, J. R. M. Ruas, F. P. Monção, L. A. Borges, J. P. S. Rigueira, J. C. P. Ramos, and V. M. Gomes. 2019. Feed restriction of F1 Holstein $\times$ Zebu cows in the final third of lactation modifies intake, nutrient digestibility, feeding behav- 
ior, and performance. Rev. Bras. Zootec. 48:e20180130. https://doi .org/10.1590/rbz4820180130.

Sauvant, D., P. Chapoutot, I. Ortigues-Marty, and P. Nozière. 2018. Energy supply. Pages 43-59 in INRA Feeding System for Ruminants. INRA, ed. Wageningen Academic Publishers, Wageningen, the Netherlands. https://doi.org/10.3920/978-90-8686-872-8.

USDA Economic Research Service (USDA ERS). 2019. Milk Cost of Production Estimates- 2016 base, Milk cost of production by State. Accessed Sep. 19, 2019. https://www.ers.usda.gov/data -products/milk-cost-of-production-estimates/.

Vandehaar, M. J. 1998. Efficiency of nutrient use and relationship to profitability on dairy farms. J. Dairy Sci. 81:272-282. https://doi .org/10.3168/jds.S0022-0302(98)75576-6.
Volden, H. 1999. Effects of level of feeding and ruminally undegraded protein on ruminal bacterial protein synthesis, escape of dietary protein, intestinal amino acid profile, and performance of dairy cows. J. Anim. Sci. 77:1905-1918. https://doi.org/10.2527/1999 $.7771905 \mathrm{x}$

\section{ORCIDS}

A. Fischer $\odot$ https://orcid.org/0000-0003-4694-822X

N. Edouard ๑ https://orcid.org/0000-0002-6158-0956

P. Faverdin (ㄴ) https://orcid.org/0000-0003-3883-8389 